\title{
Clinical experience in the treatment of acromegaly - 5 years follow-up results
}

\author{
-Zelija Velija-Asimi ${ }^{1}$, Snjezana Pejicic ${ }^{2}$ \\ 1University Clinical Centre of Sarajevo, Bosnia and Herzegovina \\ ${ }^{2}$ Clinical Centre of Banja Luka, Bosnia and Herzegovina
}

\section{Objective}

The aim of this study was to evaluate our clinical experience in the treatment of acromegaly during 5-year follow up period.

\section{Methods}

Seventeen acromegaly patients (11 women and 6 men) monitored during 5 year follow-up period (2009.20014). A level of growth hormone $(\mathrm{GH})$ of $<2.5 \mathrm{ng} / \mathrm{ml}$ and the normal insulin-like growth factor (IGF) range were considered as the criterion for remission. The $\mathrm{GH}$ level and IGF-1 level were evaluated every 6 months, while magnetic resonance imaging was taken every year during follow-up period. Ten patients were treated with surgical and octreotide treatment. One patient was treated with surgical, octreotide and gamma-knife treatment and six patients were treated only with octreotide LAR.

\section{Results}

All patients had growth in hands and feet and typical facial asymmetry in the beginning of the study. Six patients had diabetes mellitus (35\%), four patients had hyperprolactinemia (24\%), two patients had hypothyroidism (12\%) and five of patients had hypertension (29\%). Visual field defect was in 5 patients (29\%). Microadenomas founded in 6 patients and macroadenomas in 11 patients. Nine patients were treated by trans-sphenoidal surgery. One of them was cured, 3 patients developed postoperative pituitary deficiency. Two patients were treated by transcranial surgery, but not cured. One of them was treated by Gamma Knife radiosurgery and after that developed pituitary deficiency. Sixteen out of seventeen acromegaly patients were treated by octreotide (6 of patients as primary therapy and 10 patients as

secondary therapy after surgery).

\section{Biochemical remission and tumor size} reducing during follow-up period of 5 years

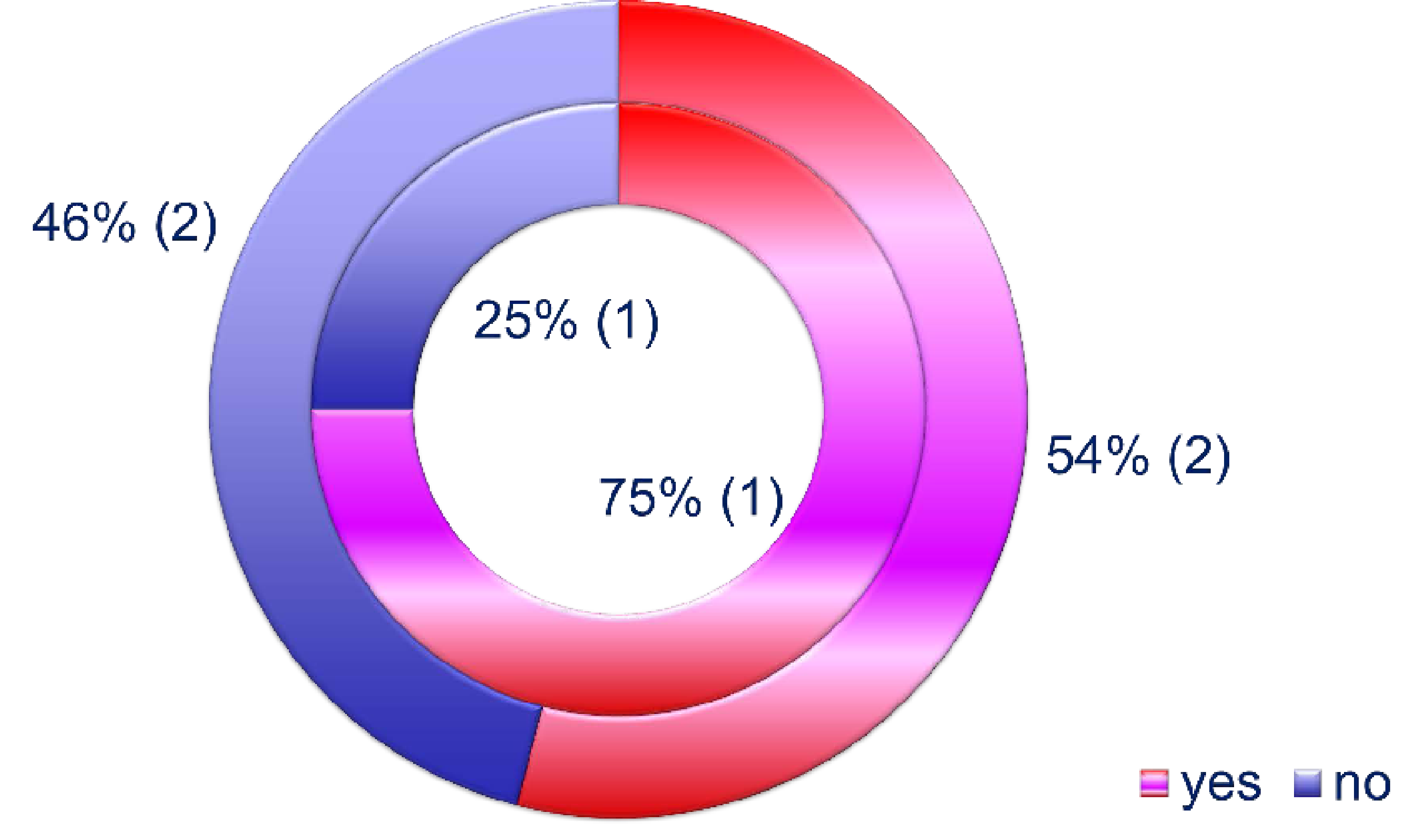

Figure 1. Biochemical remission (1) at $75 \%$ and tumor size reducing (2) at $54 \%$ of patients treated by octreotide LAR during follow-up period of 5 years

\section{The treatment was successful withdrawn during follow-up period of 5 years}

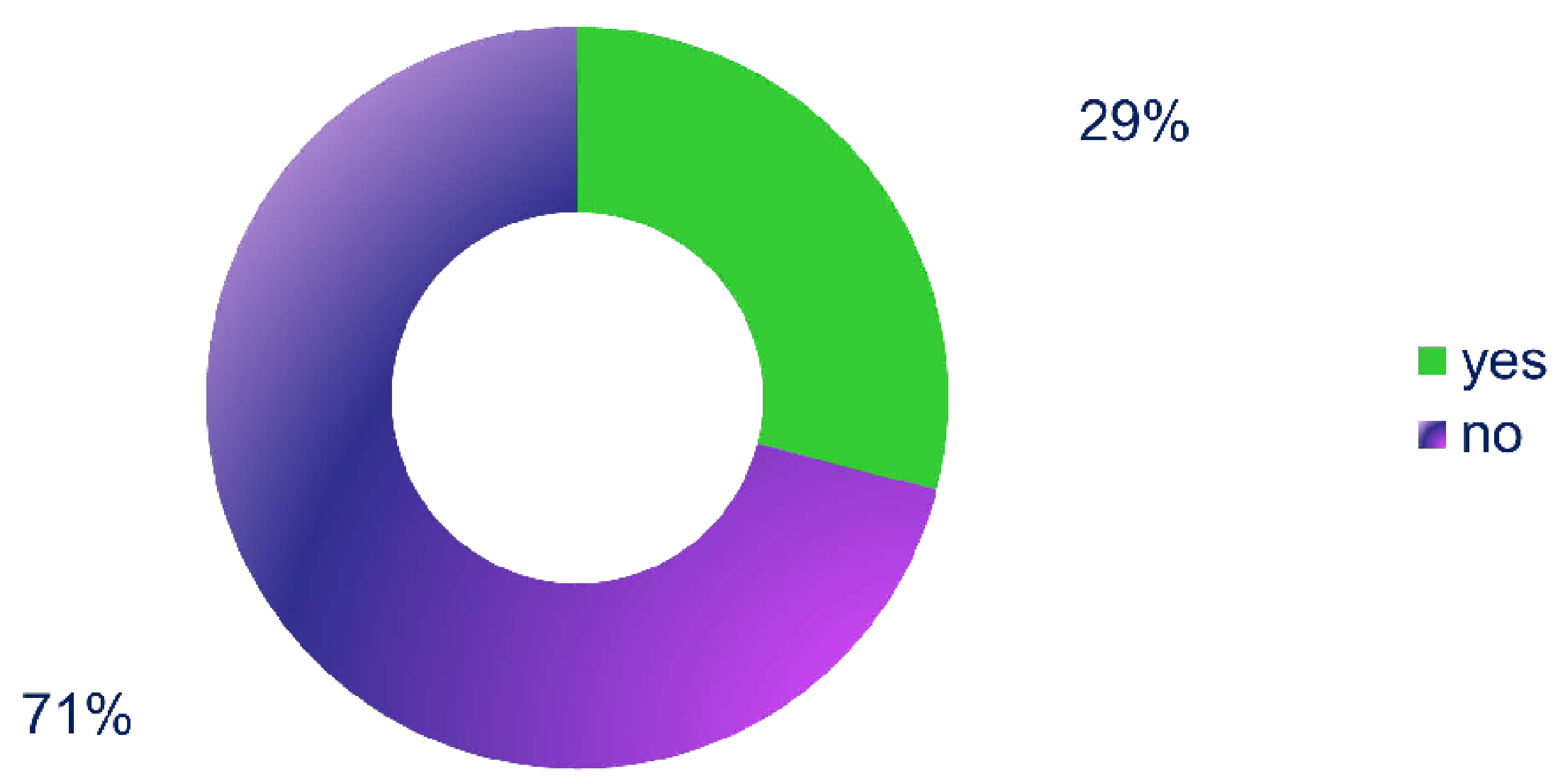

Figure 2. The treatment by octreotide LAR was successful withdrawn at $29 \%$ patients during follow-up period of 5 years

Biochemical remission was achieved in 12 of 16 patients $(75 \%)$ who received octreotide treatment. Tumor size decrease was achieved in $54 \%$ of patients. (Figure 1). The treatment was successful withdrawn at five patient (29\%) without recurrence for 2-3 years follow-up (Figure 2). One patient passed away due to co-morbidities and at one patient treatment was cancelled due to kidney cancer. Only one patient $(6,25 \%)$ who regularly used high dosage of octreotide has uncontrolled acromegaly.

\section{Conclusion}

Our findings demonstrated that octreotide LAR treatment successfully controlls clinical, biochemical and neuroradiological parameters.

Keywords: acromegaly, human growth hormone, insulin-like growth factor I, octreotide, pituitary adenoma

\section{References}

Evran M, Sert M, Tetiker T. Clinical experiences and success rates of acromegaly treatment: the single center results of 62 patients. BMC Endocr Disord. 2014 Dec 16;14(1):97. doi: 10.1186/1472-6823-14-97.

Giustina A, Mazziotti G, Maffezzoni F, Amoroso V, Berruti A. Investigational drugs targeting somatostatin receptors for treatment of acromegaly and neuroendocrine tumors. Expert Opin Investig Drugs. 2014 Dec;23(12):1619-35. doi: 10.1517/13543784.2014.942728.

Espinosa de los Monteros AL1, Carrasco CA, Albarrán AA, Gadelha M, Abreu A, Mercado M. The role of primary pharmacological therapy in acromegaly. Pituitary. 2014 Jan;17 Suppl 1:S4-10. doi: 10.1007/s11102-013-0530-0. 